\title{
Analisis Probabilitas Pemilihan Moda Pesawat Terbang dan Kapal Laut pada Rute Fakfak Sorong dengan Metode Revealed Preference
}

\author{
Ratna S. Sari Tuhepaly ${ }^{1}$, Hera Widyastuti ${ }^{1, *}$ \\ Departemen Teknik Sipil, Institut Teknologi Sepuluh Nopember, Surabaya ${ }^{1}$ \\ Koresponden*, Email: hera.widyastuti@yahoo.co.uk
}

\begin{tabular}{|c|c|c|}
\hline & Info Artikel & Abstract \\
\hline Diajukan & 15 Januari 2019 & Fakfak Regency is an archipelago. Sea transportation and air transportation facilities are \\
\hline Diperbaiki & 01 Februari 2019 & the means of transportation between districts. The Fakfak-Sorong route is the most crowded \\
\hline Disetujui & 07 Februari 2019 & $\begin{array}{l}\text { route. Sorong City is not only a destination city but also a link to other cities. Therefore, in } \\
\text { this study, a descriptive analysis is needed to determine the socio-economic characteristics of } \\
\text { passengers in choosing the mode between aircraft and ships on the Fakfak-Sorong route. } \\
\text { Also, binary logistic regression analysis was carried out using revealed preference technique } \\
\text { to obtain the probability value of passengers in the choice between aircraft and ship modes. }\end{array}$ \\
\hline \multicolumn{2}{|c|}{$\begin{array}{l}\text { Keywords: descriptive analysis, binary } \\
\text { logistic regression analysis, revealed } \\
\text { preference, probability }\end{array}$} & $\begin{array}{l}\text { The probability result of aircraft mode choice is } 61.75 \% \text {, which is affected by income variable } \\
\text { greater than Rp. } 5.000 .000,-. \text { Furthermore, the probability result of ship mode choice is } \\
86.36 \% \text {, which is affected by income variable less than } R p .1 .500 .000,-.\end{array}$ \\
\hline
\end{tabular}

\begin{abstract}
Abstrak
Kabupaten Fakfak merupakan daerah kepulauan. Sarana angkutan laut dan angkutan udara menjadi alat transportasi antar kabupaten. Rute Fakfak-Sorong menjadi rute paling padat. Kota Sorong bukan hanya menjadi kota tujuan, tetapi juga menjadi Penghubung ke kota lainnya. Oleh karena itu dalam penelitian ini perlu dilakukan analisis deskriptif untuk mengetahui karakteristik sosio-ekonomi penumpang dalam memilih moda pesawat terbang dan kapal laut pada rute Fakfak-Sorong. Selain itu dilakukan analisis regresi logistik biner dengan menggunakan teknik revealed preference untuk mendapatkan besaran nilai probabilitas penumpang dalam pemilihan moda pesawat terbang dan kapal laut. Hasil probabilitas pemilihan moda pesawat terbang terbesar ada pada variabel pendapatan diatas Rp. 5.000.000,- yaitu 61.75\%, sedangkan hasil probabilitas pemilihan moda kapal laut terbesar ada pada variabel variabel pendapatan dibawah $R p$. 1.500.000,- yaitu $83.36 \%$.
\end{abstract}

Kata kunci: analisis deskriptif, analisis regresi logistik biner, revealed preference, probabilitas

\section{Pendahuluan}

Kabupaten Fakfak merupakan daerah kepulauan yang mempunyai luas wilayah $14.320 \mathrm{~km}^{2}$ dengan topografi didominasi oleh pesisir dan lereng/punggung bukit [1]. Sarana angkutan laut dan angkutan udara menjadi alat transportasi antar kabupaten. Berdasarkan data sekunder yang diperoleh dari instansi pelayaran dan penerbangan di Kabupaten Fakfak bahwa rute Fakfak-Sorong adalah rute yang paling padat yang melayani sekitar 2105 penumpang setiap bulannya jika dibandingkan dengan rute Fakfak-Manokwari sekitar 410 penumpang [2]. Kota Sorong bukan hanya menjadi kota tujuan, tetapi juga menjadi penghubung ke kota lainnya.

Pertimbangan pelaku perjalanan rute Fakfak-Sorong dalam pemilihan moda pesawat tebang adalah frekuensi penerbangan satu kali sehari dengan kapasitas yaitu \pm 60 penumpang yang ditempuh dalam waktu \pm 45 menit dan biaya sekitar Rp. 814.000,- [2], [3], selain itu faktor cuaca juga sangat mempengaruhi sehingga sering terjadi penundaan keberangkatan Sedangkan pertimbangan dalam pemilihan moda kapal laut adalah frekuensi pelayaran dua kali dalam seminggu yang ditempuh dalam waktu antara 14 jam sampai 17 jam perjalanan [4], [5].

Oleh karena itu dalam penelitian ini perlu dilakukan analisis deskriptif untuk mengetahui karakteristik sosio-ekonomi penumpang dalam memilih moda pesawat terbang dan kapal laut pada rute Fakfak-Sorong. Selain itu dilakukan analisis regresi logistik biner dengan menggunakan teknik revealed preference untuk mendapatkan besaran nilai probabilitas penumpang dalam pemilihan moda pesawat terbang dan kapal laut pada rute Fakfak-Sorong.

\section{Metode}

Tahapan awal dalam penelitian ini adalah identifikasi masalah dan studi literatur mengenai analisis probabilitas menggunakan model logit biner dan metode revealed preference. Selanjutnya mengumpulkan data-data yang dibutuhkan untuk proses analisis. Data yang dibutuhkan berupa data primer dan data sekunder. Data primer adalah data yang 
diperoleh secara langsung dari pengguna moda pesawat terbang dan kapal laut dengan cara survei kuesioner dan wawancara, sedangkan data sekunder adalah data penunjang data primer yang diperoleh dari instansi-instansi dan pihak-pihak terkait dalam penelitian ini.

Penarikan sampel menggunakan teknik nonprobability Sampling [6]. Penentuan jumlah sampel dilakukan dengan cara mengambil nilai rata-rata dari hasil perhitungan tiga formula yaitu rumus Slovin [7], tabel Krejcie dan Morgan [8], dan persentase menurut Yount [9] dari jumlah populasi dalam satu minggu. Dimana jumlah populasi pesawat terbang rute Fakfak-Sorong per bulan Oktober 2018 yang diperoleh dari Unit Penyelenggara Bandara Udara Torea Fakfak yaitu 2105 penumpang/bulan, polpulasi kapal laut rute Fakfak Sorong per bulan September 2018 yang diperoleh dari PT. Pelayaran Nasional Indonesia Cabang fakfak yaitu 878 penumpang/bulan, dan populasi kapal laut rute Fakfak-Sorong per bulan Juli 2018 yang diperoleh dari Kantor Kesyahbandaran dan Otoritas Pelabuhan Fakfak yaitu 339 penumpang/bulan. Hasil dari penentuan jumlah sampel dapat dilihat pada Tabel 1, total sampel penelitian adalah 263 responden yang terdiri dari 119 responden moda pesawat terbang dan 144 responden moda kapal laut (77 responden kapal pelni dan 67 responden kapal Ferry).

Tabel 1. Jumlah Sampel Penumpang

\begin{tabular}{ccccc}
\hline Moda & $\begin{array}{c}\text { Rumus } \\
\text { Slovin } \\
(\mathrm{n})\end{array}$ & $\begin{array}{c}\text { Tabel } \\
\text { Krejcie \& } \\
\text { Morgan (n) }\end{array}$ & $\begin{array}{c}\text { Persentase } \\
\text { Yount (n) }\end{array}$ & $\begin{array}{c}\text { Jumlah } \\
\text { Sampel } \\
\text { Rata-Rata }\end{array}$ \\
\hline $\begin{array}{c}\text { Pesawat } \\
\text { Terbang } \\
\text { Kapal Laut } \\
\text { (Pelni) } \\
\text { Kapal Laut } \\
\text { (Ferry) }\end{array}$ & 84 & 222 & 53 & 119 \\
\hline
\end{tabular}

Pembuatan kuesioner menggunakan teknik revealed preference [10],[11]. Survei dengan teknik revealed preverence untuk pemilihan moda rute Fakfak-Sorong tergantung pada alternatif yang tersedia yaitu moda pesawat terbang dan moda kapal laut. Teknik revealed preference merupakan pendekatan terhadap responden untuk mengetahui respon mereka sesuai dengan situasi yang mereka hadapi saat ini dalam keadaan sebenarnya atau nyata (bagaimana preferensinya terhadap moda yang digunakan untuk rute Fakfak-Sorong).

Tabel 2 menunjukkan atribut dari moda pesawat dan kapal laut yang diperkirakan mempengaruhi keputusan dalam pemilihan moda.
Tabel 2. Atribut Moda Pesawat Terbang dan Kapal Laut

\begin{tabular}{ccc}
\hline Atribut & $\begin{array}{c}\text { Moda Pesawat } \\
\text { Terbang }\end{array}$ & Moda Kapal Laut \\
\hline Biaya perjalanan (Rp) & 817.000 & $124.000-250.000$ \\
Waktu tempuh & 45 menit & 14 jam -17 jam \\
Frekuensi per minggu & 7 kali & 2 kali \\
\hline
\end{tabular}

Data-data yang didapatkan dari survei kuesioner dan wawancara kemudian dianalisis dengan analisis statistik deskriptif [12],[13],[14],[15] yang digambarkan dalam bentuk grafik diagram batang. Grafik diagram batang tersebut menjelaskan karakteristik sosial-ekonomi penumpang moda pesawat terbang dan kapal laut Fakfak-Sorong. Dari grafik diagram batang tersebut, kita juga akan mengetahui persentase nilai tertinggi dari masing-masing karakteristik penumpang pesawat terbang dan kapal laut dalam pemilihan moda.

Analisis selanjutnya adalah analisis regresi logistik biner [16],[17]. Analisis regresi logit biner (binary logistic regression) digunakan untuk mengetahui persentase probabilitas responden yang memilih moda pesawat terbang dan kapal laut. Selain itu, analisis regresi logistik biner juga dapat digunakan untuk mengetahui variabel/atribut yang dominan mempengaruhi responden untuk menggunakan moda pesawat terbang dan kapal laut.

Untuk menentukan perkiraan nilai probabilitas pemilihan moda dapat dihitung dengan menggunakan rumus berikut [18],[19]:

$\ln \frac{p}{1-p}=\beta_{0}+\beta_{0}+\beta_{1} X_{1}+\beta_{2} X_{2}+\cdots+\beta_{k} X_{k}$

dimana :

$\beta_{0}+\beta_{1}+\beta_{2}+\beta_{k}=$ Data yang bersifat biner dengan dua respon, misalnya pesawat terbang (0), kapal laut (1). Data yang bersifat biner merupakan variabel terikat.

$(X)=$ Merupakan variabel bebas, yang terdapat faktor pengaruh dalam pemilihan moda.

Setelah perhitungan ini selesai maka didapatkan hasil nilai (exp) eksponensial yang akan dipakai untuk menghitung perkiraan besar nilai probabilitas dengan menggunakan rumus sebagai berikut [18],[20],[21],[22]:

$\left.P_{(\text {Pesawat }}\right)=\frac{1}{1+\exp ^{\log i t(p)}}$

$P_{(\text {Kapal })}=\frac{\exp ^{\operatorname{logit}(p)}}{1+\exp \operatorname{logit}(p)}$

Untuk menentukan faktor yang berpengaruh antara variabel bebas dengan variabel terikatnya, dapat ditentukan 
dengan membandingkan nilai signifikannya yaitu jika nilai sig. $<\alpha$, dengan toleransi nilai $\alpha=0,05 \%$, maka variabel tersebut berpengaruh, namun jika nilai sig. $>\alpha$ maka variabel tersebut tidak berpengaruh.

\section{Hasil dan Pembahasan}

Survei dilakukan dibeberapa lokasi untuk meninjau moda pesawat terbang dan kapal laut, yaitu di ruang tunggu terminal penumpang Bandara Torea Fakfak untuk mengetahui karakteristik sosial-ekonomi penumpang dalam memilih moda pesawat terbang rute Fakfak-Sorong. Di ruang tunggu terminal penumpang Pelabuhan Fakfak dan di Kapal KMP. Kalabia untuk mengetahui karakteristik sosial-ekonomi penumpang dalam memilih moda kapal laut rute Fakfak-Sorong.

Survei pesawat terbang dilakukan selama 6 (enam) kali jadwal penerbangan dan survei kapal laut dilakukan 3 (tiga) kali jadwal pelayaran untuk rute Fakfak-Sorong. Survei wawancara dilakukan kurang lebih 9 hari untuk mendapatkan jumlah responden pesawat terbang dan kapal laut yang sesuai dengan tujuan dan maksud penelitian.

Pengisian kuesioner dilakukan secara langsung untuk masing-masing responden. Hal ini dilakukan dengan tujuan agar tidak terjadi kesalahan penafsiran pertanyaan dalam mengisi kuesioner.

\section{Karakteristik Penumpang}

Dari hasil analisis deskriptif, didapat karakteristik berdasarkan jenis kelamin penumpang untuk moda pesawat terbang adalah pria $66 \%$ dan wanita $34 \%$. Sedangkan jenis kelamin penumpang untuk moda kapal laut adalah pria $55 \%$ dan wanita 45\%. Data karakteristik dapat dilihat pada Gambar 1.

Karakteristik berdasarkan usia penumpang untuk moda pesawat terbang adalah $41 \%$ usia antara 44-56 tahun, 34\% 31-43 tahun, 18\% 18-30 tahun, 5\% diatas 56 tahun dan 1\% dibawah 18 tahun. Sedangkan usia penumpang untuk moda kapal laut adalah 31\% usia antara 31-43 tahun, 27\% 18-30 tahun, 25\% 44-56 tahun, 11\% diatas 56 tahun, dan 6\% dibawah 18 tahun. Data karakteristik dapat dilihat pada Gambar 2.

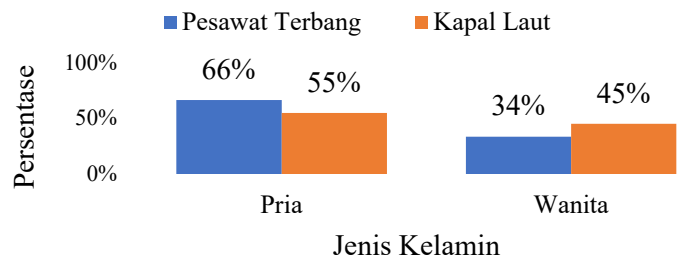

Gambar 1. Grafik Karakteristik Penumpang Berdasarkan Jenis Kelamin

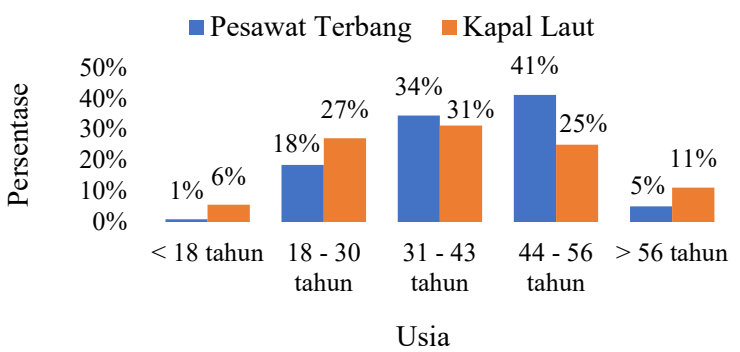

Gambar 2. Grafik Karakteristik Penumpang Berdasarkan Usia

Karakteristik berdasarkan pekerjaan penumpang untuk moda pesawat terbang adalah pekerjaan $43 \%$ PNS/Pegawai BUMN/TNI/POLRI, 21\% pengusaha/pedagang, 14\% pegawai swasta, $18 \%$ pekerjaan lainnya dan $3 \%$ pelajar/mahasiswa. Sedangkan pekerjaan penumpang untuk moda kapal laut $42 \%$ adalah pekerjaan lainnya, 34\% PNS/Pegawai BUMN/TNI/POLRI, $10 \%$ pelajar/mahasiswa, $8 \%$ pegawai swasta dan $6 \%$ pengusaha/pedagang. Data karakteristik dapat dilihat pada Gambar 3.

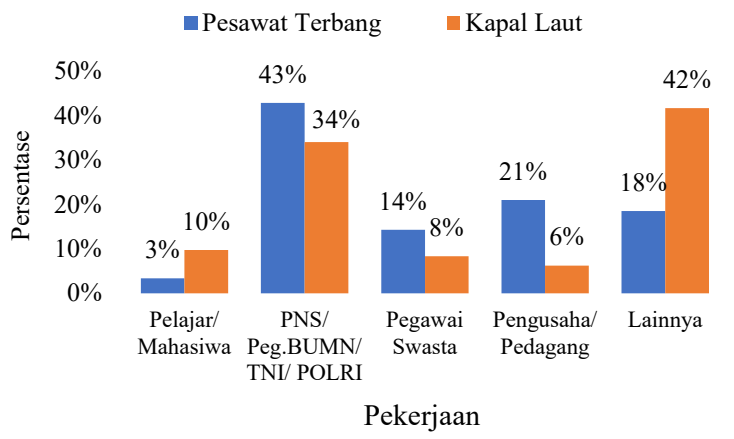

Gambar 3. Grafik Karakteristik Penumpang Berdasarkan Pekerjaan

Karakteristik berdasarkan pendapatan penumpang untuk moda pesawat terbang adalah $64 \%$ pendapatan diatas Rp.5 juta, 24\% Rp. 3.6 juta-Rp. 5 juta, 7\% Rp. 1.5 juta-Rp. 3.5 juta, dan 5\% dibawah Rp.1.5 juta. Sedangkan pendapatan penumpang untuk moda kapal laut adalah $38 \%$ pendapatan antara Rp. 3.6 juta-Rp. 5 juta, 22\% diatas Rp.5 juta, 20\% dibawah Rp.1.5 juta, dan 19\% Rp. 1.5 juta - Rp. 3.5 juta. Data karakteristik dapat dilihat pada Gambar 4.

\section{Probabilitas Pemilihan Moda}

Berdasarkan hasil uji wald dengan regresi logistik biner untuk variabel bebas (independent variable) terhadap variabel terikat (dependent variable), maka dapat diketahui bahwa variabel bebas yang berpengaruh secara signifikan terhadap variabel terikatnya karena nilai $p$-value uji wald sig. $<\alpha$. 
Dimana nilai $\alpha=0,05$. Asumsi yang dapat diambil dalam pengujian dengan melihat nilai p-value:

- Tolak $\mathrm{H}_{0}$ bila signifikan $\leq \alpha$, dapat disimpulkan bahwa variabel bebas berpengaruh signifikan terhadap variabel terikat.

- Terima $\mathrm{H}_{0}$ bila signifikan $>\alpha$, dapat disimpulkan bahwa variabel bebas tidak berpengaruh signifikan terhadap variabel terikat.

Variabel Bebas yang Berpengaruh dengan Pemilihan Moda Pesawat Terbang dan Kapal Laut adalah variabel pendapatan, dapat dilihat pada Tabel 7.

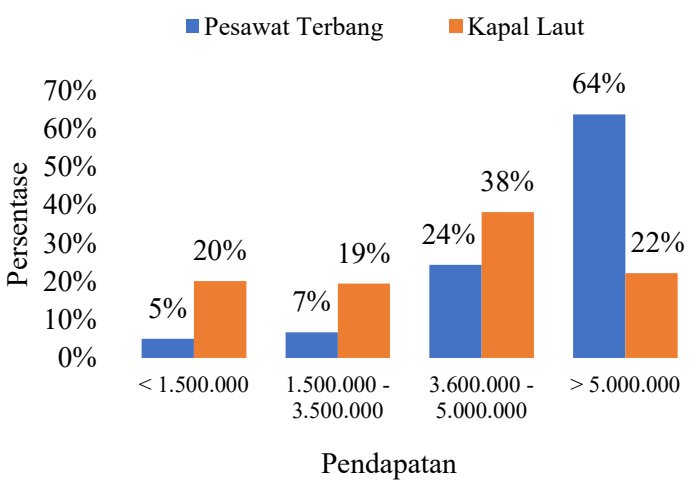

Gambar 4. Grafik Karakteristik Penumpang Berdasarkan Pendapatan

Tabel 7. Variabel Bebas yang Berpengaruh dengan Pemilihan Moda Pesawat Terbang dan Kapal Laut

\begin{tabular}{cccc}
\hline Variabel Bebas & $p$-value & $\alpha=5 \%$ & Keputusan \\
\hline Jenis Kelamin & 0.058 & 0.05 & Terima $\mathrm{H}_{0}$ \\
Usia & 0.061 & 0.05 & Terima $\mathrm{H}_{0}$ \\
Pekerjaan & 0.112 & 0.05 & Terima $\mathrm{H}_{0}$ \\
Pendapatan & 0.000 & 0.05 & Tolak $\mathrm{H}_{0}$ \\
\hline
\end{tabular}

Tabel 7 menunjukkan bahwa variabel pendapatan berpengaruh signifikan terhadap variabel terikat pemilihan moda pesawat terbang dan kapal laut karena nilai p-value uji wald sig. $<\alpha$ yaitu $0.000<0.005$ sehingga keputusan adalah $\mathrm{H}_{0}$ ditolak. Dimana nilai $\alpha=0,05$.

Untuk menganalisis seberapa besar peluang pelaku perjalanan dalam pemilihan moda pesawat terbang ataupun moda kapal rute Fakfak-Sorong dilakukan dengan metode regresi logistik biner, dimana variabel bersifat dikotomi dengan dua kemungkinan yaitu 0: Memilih moda pesawat terbang dan 1: Memilih moda kapal laut.

Analisis ini bertujuan untuk mengetahui pengaruh kemungkinan penggunaan moda antara variabel yang banyak mempengaruhi pemilihan suatu moda yaitu variabel pendapatan. Berikut ini adalah perhitungan probabilitas pemilihan moda pesawat terbang dan kapal laut dengan variabel bebas yang paling berpengaruh terhadap pemilihan moda pesawat terbang dan kapal laut:

\section{Variabel Pendapatan}

Hasil uji wald dengan regresi logistik pada variabel tersebut dapat dilihat pada Tabel 8.

Tabel 8. Hasil Uji Wald Regresi Logistik Biner untuk Variabel Pendapatan

\begin{tabular}{|c|c|c|c|c|c|c|c|c|c|}
\hline \multicolumn{10}{|c|}{ Variables in the Equation } \\
\hline & & \multirow[t]{2}{*}{$\mathrm{B}$} & \multirow[t]{2}{*}{ S.E. } & \multirow[t]{2}{*}{ Wald } & \multirow[t]{2}{*}{ df } & \multirow[t]{2}{*}{ Sig. } & \multirow[t]{2}{*}{$\operatorname{Exp}(B)$} & \multicolumn{2}{|c|}{$\begin{array}{c}95 \% \text { C.I.for } \\
\text { EXP(B) }\end{array}$} \\
\hline & & & & & & & & Lower & Upper \\
\hline \multirow{2}{*}{$\begin{array}{l}\text { Step } \\
1^{\mathrm{a}}\end{array}$} & Pendapatan & -.775 & .143 & 29.266 & 1 & .000 & .461 & .348 & .610 \\
\hline & Constant & 2.621 & .482 & 29.519 & 1 & .000 & 13.744 & & \\
\hline
\end{tabular}

Persamaan pemodelan logit pada variabel bebas tersebut adalah sebagai berikut:

$$
\begin{aligned}
\operatorname{logit}(P) & =\ln \frac{p}{1-p} \\
& =\beta_{0}+\beta_{1} X_{1}+\beta_{2} X_{2}+\beta_{3} X_{3}+\cdots+\beta_{k} X_{k} \\
& =2.621-0.775_{\text {Pendapatan }}
\end{aligned}
$$

Probabilitas untuk pendapatan dibawah Rp. 1.000.000,- :

$$
\begin{aligned}
\left.P_{(\text {Pesawat }}\right) & =\frac{1}{1+\exp ^{\log i t(p)}} \\
& =\frac{1}{1+\exp ^{1.846}}=\frac{1}{1+2.718^{1.846}} \\
& =0.1364 \approx 13.64 \% \\
P_{\text {(Kapal) }}= & \frac{\exp ^{\operatorname{logit}(p)}}{1+\exp ^{\log i t(p)}} \\
= & \frac{\exp ^{1,846}}{1+\exp ^{1,846}}=\frac{2.718^{1,846}}{1+2.718^{1,846}} \\
= & 0.8636 \approx 86.36 \%
\end{aligned}
$$

Probabilitas untuk pendapatan antara Rp. 1.500.000,- sampai Rp. 3.500.000,-:

$$
\begin{aligned}
\left.P_{(\text {Pesawat }}\right) & =\frac{1}{1+\exp \operatorname{logit}^{\log }} \\
& =\frac{1}{1+\exp ^{1.071}}=\frac{1}{1+2.718^{1.071}} \\
& =0.2552 \approx 25.52 \% \\
P_{\text {(Kapal) }}= & \frac{\exp ^{\operatorname{logit}(p)}}{1+\exp ^{\operatorname{logit}(p)}}
\end{aligned}
$$




$$
\begin{aligned}
& =\frac{\exp ^{1.071}}{1+\exp ^{1.071}}=\frac{2.718^{1.071}}{1+2.718^{1.071}} \\
& =0.7448 \approx 74.48 \%
\end{aligned}
$$

Probabilitas untuk pendapatan antara Rp. 3.600.000,- sampai Rp. 5.000.000,-:

$$
\begin{aligned}
\left.P_{(\text {Pesawat }}\right) & =\frac{1}{1+\exp ^{\log i t(p)}} \\
& =\frac{1}{1+\exp ^{0.296}}=\frac{1}{1+2.718^{0.296}} \\
& =0.4265 \approx 42.65 \% \\
P_{\text {(Kapal) }}= & \frac{\exp ^{\operatorname{logit}(p)}}{1+\exp ^{\log i t(p)}} \\
= & \frac{\exp ^{1.071}}{1+\exp ^{0.296}}=\frac{2.718^{0.296}}{1+2.718^{0.296}} \\
= & 0.5735 \approx 57.35 \%
\end{aligned}
$$

Probabilitas untuk pendapatan diatas Rp. 5.000.000,-:

$$
\begin{aligned}
\left.P_{(\text {Pesawat }}\right) & =\frac{1}{1+\exp ^{\log i t(p)}} \\
& =\frac{1}{1+\exp ^{-0.479}}=\frac{1}{1+2.718^{-0.479}} \\
& =0.6175 \approx 61.75 \% \\
P_{(\text {Kapal })}= & \frac{\exp ^{\operatorname{logit}(p)}}{1+\exp ^{\operatorname{logit}(p)}} \\
= & \frac{\exp ^{-0.479}}{1+\exp ^{-0.479}}=\frac{2.718^{-0.479}}{1+2.718^{-0.479}} \\
= & 0.3825 \approx 38.25 \%
\end{aligned}
$$

Hasil perhitungan probabilitas berdasarkan variabel pendapatan dapat dilihat pada Gambar 5.

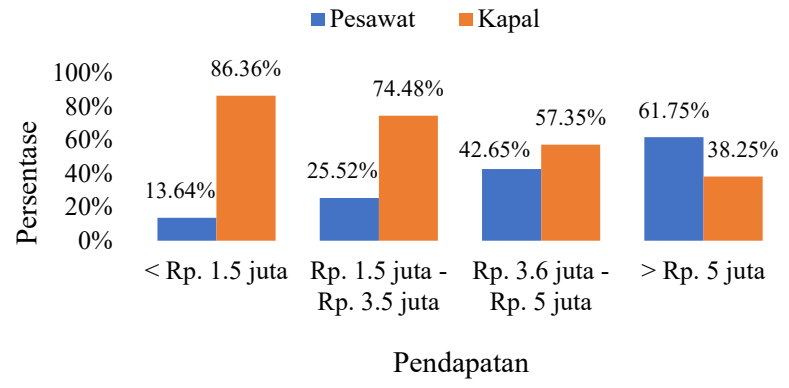

Gambar 5. Grafik Probabilitas Pemilihan Moda Pesawat Terbang dan Kapal Laut Berdasarkan Variabel Pendapatan

Dari Gambar 5 terlihat bahwa semakin tinggi pendapatan, maka probabilitas pemilihan moda pesawat terbang akan semakin besar. Sedangkan semakin kecil pendapatan, maka nilai probabilitas kapal laut akan semakin besar.
Sebelum model dinyatakan layak, model tersebut harus diuji statistik sesuai Tabel 9. Pengujian model regresi logistik biner menggunakan uji Hosmer and Lemeshow Test, dengan asumsi:

- $\mathrm{H}_{0}$ : Model telah cukup mampu menjelaskan data (Goodness of Fit)

- $\mathrm{H}_{1}$ : Model tidak cukup mampu menjelaskan data

Kriteria uji:

- Terima $\mathrm{H}_{0}$ jika nilai $p$-value sig. $>0.05$

- Tolak $\mathrm{H}_{0}$ jika nilai p-value sig. $<0.05$

Tabel 9. Hosmer and Lemeshow Test Berdasarkan Variabel Pendapatan

\begin{tabular}{lrrrr}
\hline Step & Chi-square & df & & \multicolumn{1}{c}{ Sig. } \\
\hline 1 & .724 & & 2 & .696 \\
\hline
\end{tabular}

Dari Tabel 9 terlihat bahwa nilai chi square $0.724<$ nilai chi square tabel ( $\mathrm{df}=2$ dengan signifikasi 0.05 ) yaitu 0.724 $<5.991$ atau nilai sig. $0.696>0.05$ sehingga keputusan adalah $\mathrm{H}_{0}$ diterima, dengan tingkat keyakinan 95\%, dapat diyakini bahwa model regresi logistik yang digunakan cukup mampu menjelaskan data/sesuai pengujian. Hal ini membuktikan bahwa model regresi logistik layak untuk di interpretasikan.

Classification plot untuk Variabel Pendapatan menunjukkan bahwa regresi logistik yang digunakan telah cukup baik karena mampu menebak dengan benar $66.5 \%$ kondisi yang terjadi, dapat dilihat pada Tabel $\mathbf{1 0 .}$

Tabel 10. Classification plot untuk Variabel Pendapatan

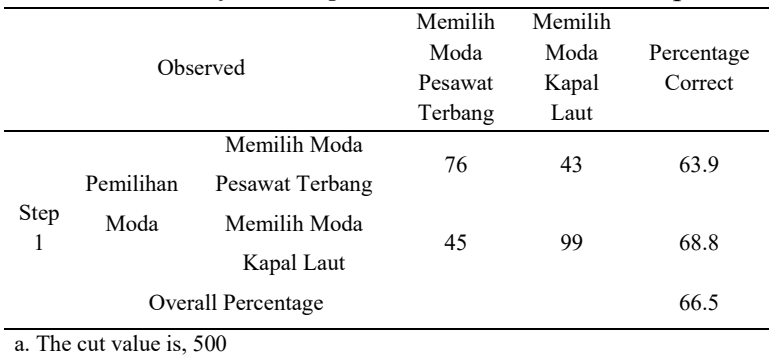

Dari hasil perhitungan di peroleh bahwa penumpang dengan pendapatan diatas Rp. 5.000.000,- mempengaruhi kemauan penumpang menggunakan moda pesawat terbang dengan nilai probabilitas $61.75 \%$. Sedangkan pendapatan dibawah Rp. 1.500.000,- mempengaruhi kemauan penumpang menggunakan moda kapal laut dengan nilai probabilitas $86.36 \%$. 


\section{Simpulan}

Berdasarkan hasil dan pembahasan dapat disimpulkan bahwa karakteristik penumpang yang paling dominan terhadap pengaruh pemilihan moda pesawat terbang adalah $66 \%$ jenis kelamin pria, 64\% pendapatan diatas Rp. 5 juta, 43\% pekerjaan PNS/ Pegawai BUMN/ TNI/POLRI, dan 41\% usia antara 44 tahun-56 tahun.

Karakteristik penumpang yang paling dominan terhadap pengaruh pemilihan kapal laut adalah $55 \%$ jenis kelamin pria, $42 \%$ pekerjaan lainnya, 38\% pendapatan antara Rp. 3.6 juta

- Rp. 5 juta, dan $31 \%$ usia antara 31 tahun - 43 tahun.

Probabilitas pemilihan moda pesawat terbang rute Fakfak-Sorong adalah $61.75 \%$ untuk pendapatan diatas Rp. 5.000.000,-

Probabilitas pemilihan moda kapal laut rute Fakfak Sorong adalah $86.36 \%$ untuk pendapatan dibawah Rp. 1.500.000,-.

\section{Daftar Pustaka}

[1] Badan Pusat Statistik Kabupaten Fakfak, "Kabupaten Fakfak Dalam Angka 2017," Fakfak, 2018.

[2] Unit Penyelenggara Bandar Udara, "Rekapitulasi Arus Lalu Lintas Angkutan Udara," Fakfak, 2018.

[3] PT. Wings Air Cabang Fakfak, "Jadwal dan Tarif Wings Air Rute Fakfak - Sorong," Fakfak, 2018.

[4] PT. Pelni Cabang Fakfak, "Data Penumpang Tarif Tiket Kapal KM. Tidar dan KM. Tatamaelau Rute Fakfak - Sorong," Fakfak, 2018.

[5] PT. ASDP Cabang Sorong, "Lintasan. Tarif dan Jadwal KMP. Kalabia 2018,” Sorong, 2018.

[6] Sugiyono, Metode Penelitian Kuantitatif, Kualitatif dan $R \& D$. Bandung: Alfabeta, 2011.

[7] Akdon and Riduwan, Rumus dan Data dalam Aplikasi Statistik. Bandung: Alfabeta, 2005.

[8] R. V. Krecjcie and D. W. Morgan, Determining sample size for research activities. Educational and Psychological Measurement.

[9] Yount, Jumlah Populasi Kurang Dari 100 Lebih Baik Diambil Sebagai Sampel Penelitian Populasi. Jakarta: Bina Aksara, 1999.

[10] H. Widyastuti, "Valuing Motorcycle Casualties in Developing Countries using Willingness-to-Pay Method: Stated-Preference Discrete Choice Modelling Approach," [Disertasi]. Newcastle Upon Tyne (UK): School of Civil Engineering and Geosciences. Newcastle University, 2012.

[11] L. Keita, "Revealed Preference Theory, Rational, and Neoclassical Economics: Science or Ideology," J. Africa Dev., vol. XXXVII, no. 4, pp. 73-116, 2012.

[12] A. H. Huang, "Pengertian Statistik Deskriptif dan Statistik Inferensial," Statistic Consultant for Academic Research, 2016. [Online]. Available: http://www.en.globalstatistik.com/pengertianstatistik-deskriptif-dan-statistik-inferensial/.
[13] I. Hasan, Pokok-Pokok Materi Statistik 1 (Statistik Deskriptif). Jakarta: PT. Bumi AKsara, 2003.

[14] Sugiyono, Mdtode Penelitian Pendidikan. Bandung: Alfabeta, 2004.

[15] Howell, Statistical Methods For Phsycology. New York: Duxbury Press, 1982.

[16] F. Miro, Perencanaan Transportasi untuk Mahasiswa, Perencana, dan Praktisi. Jakarta: Erlangga, 2005.

[17] M. F. Nurdiansyah and H. Widyastuti, "Analisis Probabilitas Perpindahan Moda dari Bus ke Kereta Api Siliwangi Jurusan Sukabumi-Cianjur Menggunakan Analisis Regresi Logit Biner," J. Tek. ITS, vol. 4, no. 1, 2015.

[18] O. Z. Tamin, Perencanaan dan Pemodelan Transportasi, Edisi ke-2. Bandung: ITB, 2008.

[19] A. Y. Nurhidayat and H. Widyastuti, "Model of transportation mode choice between aircraft and high speed train of Jakarta-Surabaya route," IOP Conf. Ser. Earth Environ. Sci., vol. 202, no. 1, p. 012002, 2018.

[20] W. Kriswardhana and H. Widyastuti, "Probabilitas Perpindahan Moda dari Bus Ke Kereta Api dalam Rencana Re-Aktivasi Jalur Kereta Api JemberPanarukan," in Prosiding Seminar Nasional Xi, 2015.

[21] R. S. Irsadi and H. Widyastuti, "Probability Modal Transfer to the Forwarder at Terminal Lamong Bay Surabaya," ITS J. Civ. Eng., vol. 32, no. 1, May 2017.

[22] A. Soimun, "Analisis Probabilitas Perpindahan Moda Pengguna Kendaraan Pribadi (Sepeda Motor dan Mobil) ke Kereta Api Commuter Surabaya Sidoarjo," [Thesis]. Departemen Teknik Sipil. Institut Teknologi Sepuluh Nopember. Surabaya, 2018. 